\title{
Saberes aritméticos nos Programas de Ensino dos Grupos Escolares catarinenses: período 1911-1946
}

\author{
Arithmetical knowledge in Santa Catarina's primary school teaching programs \\ of 1911 and 1946
}

\author{
Thuysa Schlichting de Souza ${ }^{1}$ \\ David Antonio da Costa ${ }^{2}$
}

\begin{abstract}
Resumo
Neste artigo objetiva-se analisar as determinações oficiais para a matéria de Aritmética nos Programas de Ensino dos Grupos Escolares de Santa Catarina durante as reformas "Orestes Guimarães" (1911-1935) e "Elpídio Barbosa" (1946-1969). Busca-se evidenciar as continuidades e as rupturas entre os conteúdos e os métodos prescritos em ambas as reformas. Para tal intento, os principais referenciais teórico-metodológicos mobilizados tratam da história das disciplinas escolares e da cultura escolar. No que se refere às fontes da pesquisa, são utilizadas as legislações que consubstanciaram ambas as reformas, em especial os Programas de Ensino dos Grupos Escolares de 1914 e 1946, além das obras: Palestras sobre Ensino, de Francis Wayland Parker, e Didática da Escola Nova, de Alfredo Miguel Aguayo. A análise dos programas mostra que o ensino intuitivo representou uma inovação no pensamento pedagógico e permaneceu influenciando o currículo do ensino primário em tempos de escolanovismo.
\end{abstract}

Palavras-chave: Aritmética, pedagogia moderna, escola nova

\begin{abstract}
This abstract aims to perform an analysis of state politics applied to teaching programs on Arithmetic's subjects regarding school groups during reforms "Orestes Guimarães", based on Modern Pedagogy, and "Elpídio Barbosa", based on the new school. Authors intend to analyze continuities and breakthroughs on subjects and methods recommended on both reforms, evidencing pedagogic movements which were present at the moment. The major methodological and theoretical references applied focus on history of school subjects and school culture. Regarding research sources, mainly legislations that contributed to these reforms were used, specially Primary School teaching programs from 1914 and 1946, beyond other documents: Palestras sobre Ensino, by Francis Wayland Parker, and Didática da Escola Nova, by Alfredo Miguel Aguayo. Programs analysis states that intuitive teaching represented an innovation on pedagogic thinking and remained influencing primary school curriculum during the new school movement.
\end{abstract}

Keywords: Arithmetics, modern pedagogy; new school

\footnotetext{
${ }^{1}$ Mestre em Educação Científica e Tecnológica pela Universidade Federal de Santa Catarina. Professora substituta do Departamento de Metodologia de Ensino da Universidade Federal de Santa Catarina, Brasil. Email: thuysads@gmail.com
}

${ }^{2}$ Doutor em Educação Matemática pela Pontifícia Universidade Católica de São Paulo. Professor do Centro de Ciências da Educação e do Programa de Pós-Graduação em Educação Científica e Tecnológica da Universidade Federal de Santa Catarina. E-mail: david.costa@ufsc.br 


\section{Considerações iniciais}

A educação pública no Brasil, durante a primeira metade do século XX, foi marcada por movimentos de renovação educacional que almejavam uma nova ordem social para a nação brasileira. Na recém-instituída República, a civilização e a nacionalização do povo tornaram-se questões prioritárias para os republicanos, que enxergavam na escola uma possibilidade de transformação da sociedade. Nesse cenário, as elites republicanas do estado de Santa Catarina buscaram reorganizar a instrução pública a partir do modelo paulista. Assim, em 1911, se efetivou uma das mais importantes reformas do ensino público catarinense: a Reforma Orestes Guimarães ${ }^{3}$.

Instituída pelo governador Vidal Ramos (1910-1914), a reforma determinou mudanças significativas no ensino catarinense, tanto na sua estrutura quanto nos processos pedagógicos. A implantação dos grupos escolares entre as escolas públicas estaduais destacase como uma das maiores inovações da reforma. Segundo Nóbrega (2003), os grupos escolares inauguraram um modelo de cultura escolar específico que utilizou de uma forma de organização administrativa, programática, metodológica e espacial baseada nas concepções educacionais da Pedagogia Moderna. Pressupunha a uniformização e a seriação dos conteúdos, distribuídos racionalmente no tempo de curso, e uma homogeneização dos grupos de alunos de modo que, em cada classe, todos estivessem dentro de uma mesma faixa etária e de um mesmo grau de desenvolvimento escolar.

Embora o ensino público catarinense tenha sido reorganizado algumas vezes, nas primeiras décadas do século XX, os aspectos básicos propostos pela reforma de 1910 continuaram presentes no currículo das escolas primárias. Entretanto, foi na Reforma Elpídio Barbosa $^{4}$, em 1946, que ocorreram mudanças efetivas no curso primário, endossadas por uma nova política de ensino. As motivações dessa reorganização estavam nas Leis Orgânicas Federais $^{5}$, as quais fizeram parte de um movimento de centralização e uniformização do sistema educacional do País, que seguiu a marcha do processo de redemocratização da sociedade brasileira após o término do Estado Novo. Em âmbito estadual, a promulgação da

\footnotetext{
${ }^{3}$ O professor paulista Orestes Guimarães foi contratado pelo então governador do estado de Santa Catarina, Vidal Ramos, para comandar a reforma do ensino no estado. Por sua importante atuação, os pesquisadores da História da Educação catarinense denominaram a reforma de Instrução Pública de 1911 de "Reforma Orestes Guimarães" (Teive \& Dallabrida, 2011).

4 A reorganização do ensino catarinense no ano de 1946 teve como principal mentor o professor Elpídio Barbosa, daí decorre a denominação da reforma. De acordo com Fiori (1991), no período ininterrupto de dezembro de 1940 a dezembro de 1950, Elpídio Barbosa dirigiu o Departamento de Educação e deixou no ensino público de Santa Catarina a marca de sua personalidade.

${ }^{5}$ As Leis Orgânicas Federais do Ensino Primário foram instituídas em janeiro de 1946, mas pertencem a um conjunto maior de leis expedidas entre os anos de 1942 a 1946, conhecidas como Reforma Capanema.
}

Zetetiké, Campinas, SP, v.24, n.2, maio/ago.2016, p.208-224

ISSN 2176-1744 
http://periodicos.sbu.unicamp.br/ojs/index.php/zetetike

Lei Orgânica do Ensino Primário do Estado de Santa Catarina (Decreto S.C., 1946b) adequou o curso primário às renovações educacionais e às ideias escolanovistas.

Os elementos históricos destacados anteriormente foram narrados em pesquisas inseridas no campo da História e da História da Educação que, conforme os objetivos e os referenciais empregados, interpretam e explicitam os diversos aspectos de seu contexto. Nesse sentido, este artigo dialoga com tais estudos para produzir uma escrita histórica ${ }^{6}$ dos elementos relativos ao ensino de Aritmética nos Grupos Escolares catarinenses, tomando como pano de fundo as Reformas Orestes Guimarães e Elpídio Barbosa.

Convém salientar que os dois modelos pedagógicos - a Pedagogia Moderna e a Escola Nova - evidenciados nas referidas reformas se configuraram nos estados brasileiros, principalmente durante as cinco primeiras décadas republicanas, inclusive em Santa Catarina. Em suma, o primeiro modelo surgiu em oposição ao excessivo intelectualismo da Pedagogia Tradicional $^{7}$ e, dessa maneira, defendia veementemente o "ensino ativo", "entendido como uma forma de tornar viva a lição dos professores, mediante o uso de uma parafernália de materiais didáticos e, sobretudo, da prática das lições de coisas" (Teive, 2014, p. 155). Já a Escola Nova propunha uma "escola ativa" com ênfase na atividade e no interesse da criança.

Vidal (2005) explicita as principais ideias de ambos modelos, realçando as diferenças entre ensino ativo e escola ativa:

Apesar de surgirem como similares em muitos discursos do período, ensino ativo e escola ativa distinguiam-se na fala dos escolanovistas pela própria concepção de atividade [ênfase adicionada]. Se a primeira acepção concernia à maneira como o conteúdo deveria ser trazido ao aluno e supunha a atividade dos professores na realização de experiências e no oferecimento de imagens e objetos que concretizassem a aula; a segunda deslocava para os alunos a feitura das tarefas. Era pela ação dos métodos de projeto e centros de interesse que as crianças deveriam solucionar problemas e construir experimentos, ainda que sempre orientadas pelos docentes. (p. 11)

Mediante tais considerações e focalizando o objeto deste estudo, surge o seguinte questionamento: como os conteúdos de Aritmética e a forma de ensiná-los se caracterizavam diante dos referidos modelos pedagógicos? Dito de outra maneira, quais as transformações que ocorreram nas orientações oficiais de ensino dos grupos escolares catarinenses, no período da Reforma Orestes Guimarães e da Reforma Elpídio Barbosa, com relação à matéria de Aritmética? Evidenciam-se, dessa forma, os conteúdos de Aritmética que foram suprimidos ou mantidos de uma reforma para outra e os métodos que deveriam ser utilizados tendo em vista as vagas pedagógicas vigentes.

\footnotetext{
${ }^{6}$ Por se tratar de um estudo que assume a investigação histórica do ensino de determinados saberes matemáticos como objeto de pesquisa, a produção colabora com os estudos relacionados à História da Educação Matemática.

${ }^{7}$ Segundo Teive (2014), a pedagogia tradicional era alicerçada no verbalismo, na memorização e em práticas educativas violentas e dogmáticas.
}

Zetetiké, Campinas, SP, v.24, n.2, maio/ago.2016, p.208-224

ISSN 2176-1744 
http://periodicos.sbu.unicamp.br/ojs/index.php/zetetike

Para tal intento, privilegiam-se como fontes de análise as legislações que consubstanciaram ambas as reformas, em especial os Programas de Ensino dos Grupos Escolares de 1914 e $1946^{\circ}$. Utilizam-se ainda as obras Palestras sobre Ensino, de Francis Wayland Parker, e Didática da Escola Nova, de Alfredo Miguel Aguayo, pois esses autores desenvolveram modelos pedagógicos baseados nas concepções da pedagogia moderna e escolanovista, respectivamente.

Com relação aos referenciais teórico-metodológicos, considera-se o papel histórico da escola para a produção dos saberes escolares, como André Chervel (1990) e Julia (2001) em seus trabalhos relativos à história das disciplinas escolares ${ }^{9}$. Nesse sentido, assume-se a perspectiva orientadora que se afasta de posicionamentos de que a escola é um lugar de repetição, de pura reprodução e lugar de atraso relativamente às demandas sociais. De forma dinâmica, de construção e elaboração permanente, a escola é vista como um lugar de uma cultura particular denominada, na perspectiva de Julia, de cultura escolar.

\section{A Reforma Orestes Guimarães: os Programas de Ensino dos Grupos Escolares de 1911 e 1914}

O decreto n. 587, de 22 de abril de 1911 (Decreto S. C., 1911a) aprovou o Programa de Ensino dos Grupos Escolares e Escolas Isoladas em Santa Catarina para atender à Reforma no estado. A responsabilidade por sua idealização foi do professor Orestes Guimarães que, no cargo de diretor geral da instrução pública, tinha como atribuições apresentar e criar regulamentos, regimentos, programas e horários para o novo aparelhamento escolar (Teive \& Dallabrida, 2011). No que diz respeito aos Grupos Escolares, o programa foi dividido em quatro anos e os conteúdos prescritos categorizados em matérias.

Em relação aos saberes matemáticos, é possível identificar as matérias de Aritmética, Geometria e Desenho, contempladas em todos os anos do curso primário. Para a Aritmética, os aspectos metodológicos eram indicados superficialmente, sendo um programa de caráter mais descritivo que visava principalmente ao estabelecimento dos conteúdos de ensino. Infere-se que isso tenha ocorrido, pois, os documentos normativos de 1911 foram escritos com o intuito de instaurar uma cultura escolar própria dos Grupos Escolares e, dessa forma,

\footnotetext{
${ }^{8}$ Costa e Souza (2014) realizaram uma análise dos Programas de Ensino dos Grupos Escolares de Santa Catarina de 1911, 1914, 1920, 1928 e 1946, visando compreender como o ensino de Aritmética foi pensado e organizado oficialmente para os grupos escolares do estado desde a sua implantação até a instituição da Lei Orgânica do ensino primário.

${ }^{9}$ É importante destacar que, para o ensino primário, utiliza-se o termo "matéria" como o conjunto dos conteúdos abordados em cada ano escolar e que compõem um programa de ensino. Nesse sentido, o conceito de disciplina escolar desenvolvido por Chervel (1990) é o suporte de análise das matérias do ensino primário. Assim, identificavam-se como matéria os estudos de Português, Aritmética, Desenho, Geografia, Higiene, entre outros. Neste artigo, emprega-se a palavra "matéria" ao conjunto de saberes propostos para os Grupos Escolares de Santa Catarina.
} 
http://periodicos.sbu.unicamp.br/ojs/index.php/zetetike

coube ao programa estabelecer os conteúdos básicos para a matéria de Aritmética, e ao regimento indicar seus aspectos metodológicos.

Após alguns anos, as proposições advindas da reforma educacional de 1910 sofreram alterações e os "textos normativos foram avaliados e reestruturados, ganhando formato bem mais elaborado" (Teive \& Dallabrida, 2011, p.121). Assim, em 1913, o poder executivo autorizou a revisão dos regulamentos da Instrução Pública vigentes no estado, como o Programa de Ensino ${ }^{10}$ e o Regimento Interno dos Grupos Escolares.

Vale destacar que os reformadores catarinenses exigiam a formação na escola normal para os professores que iriam lecionar nos grupos escolares. Assim, dentro do conjunto proposto pela reforma, a escola normal deveria formar o professorado na pedagogia moderna, "pois seriam eles os responsáveis diretos pela instauração, nas novas formas escolares recéminauguradas, da nova cultura escolar, alicerçada nos pressupostos do novo método de ensino" (Teive, 2007, p. 116). Logo, como o curso normal tinha duração de três anos, os primeiros docentes formados nessa nova perspectiva passaram a atuar nas escolas a partir do ano de 1914. Em vista disso, a análise aqui proposta concentra-se nos conteúdos e nos métodos relacionados ao ensino de Aritmética no Programa dos Grupos Escolares de 1914.

\section{A Aritmética na Reforma Orestes Guimarães: por um ensino ativo}

O Programa de Ensino dos Grupos Escolares de 1914, em relação à matéria de Aritmética, apresenta os conteúdos a serem ensinados em cada ano escolar de forma detalhada, além de explicitar os passos metodológicos e descrever as fases de ensino minuciosamente. Focalizando os conteúdos aritméticos indicados no programa, o Quadro 1 sintetiza os assuntos por cada ano de escolarização.

Quadro 1 - Síntese do Programa dos Grupos Escolares Estado de Santa Catarina (Aritmética) - 1914

\begin{tabular}{|c|l|}
\hline $1^{\circ}$ ano & $\begin{array}{l}\text { A ideia de número antes de algarismo. As quatro operações simultaneamente. Os números } \\
\text { até 20. Cópia e leitura do quadro de Parker até a página } 12^{11} \text { (seção C), página } 16 \text { (seção } \\
\text { B) ou página } 20 \text { (seção A). Contar, somar, diminuir, multiplicar e dividir até } 100 \text { (apenas } \\
\text { para a seção A). }\end{array}$ \\
\hline $2^{\circ}$ ano & $\begin{array}{l}\text { Recapitulação do programa do } 1^{\circ} \text { ano. Cálculos mentais do quadro de Parker das páginas } \\
20 \text { a } 24 . \text { Formação dos números entre as dezenas, centenas e milhares; quadro de Parker } \\
\text { da página } 25 \text { a } 32 . \text { Tabuada de multiplicar e dividir até cem pelo Quadro de Parker. } \\
\text { Divisão da unidade em décimos, centésimos, milésimos. Definição de soma e subtração e } \\
\text { conhecimento de suas partes. Multiplicação e divisão com até três algarismos no } \\
\text { multiplicador e divisor. Moeda brasileira. Conhecimento prático do metro, seus } \\
\text { submúltiplos e múltiplos. }\end{array}$ \\
\hline
\end{tabular}

\footnotetext{
${ }^{10}$ Decreto n. 796, de 2 de maio de 1914 (Decreto S. C., 1914a).

${ }^{11} \mathrm{O}$ programa faz referências às páginas dos quadros de Parker, as quais podem ser verificadas no repositório institucional da UFSC. Retirado em 06 de março de 2016, de <https://repositorio.ufsc.br/handle/123456789/116708
}

Zetetiké, Campinas, SP, v.24, n.2, maio/ago.2016, p.208-224 
http://periodicos.sbu.unicamp.br/ojs/index.php/zetetike

\begin{tabular}{|c|c|}
\hline $3^{\circ}$ ano & $\begin{array}{l}\text { Multiplicação e divisão de inteiros, casos completos e casos de abreviações. Problemas } \\
\text { sobre a multiplicação e divisão, conjuntamente. Valor absoluto e relativo dos algarismos. } \\
\text { Numeração romana. Ideia da divisão da unidade. Leitura, representação e termos da fração } \\
\text { ordinária. Conhecer as frações próprias e impróprias, homogêneas e heterogêneas. Leitura } \\
\text { e escrita das frações decimais. Redução de decimais a mesma espécie. Transformar } \\
\text { frações ordinárias em decimais e vice-versa. As quatro operações sobre decimais. O } \\
\text { metro, múltiplos e submúltiplos. Medidas derivadas do metro, múltiplos e submúltiplos. } \\
\text { Conhecimento das medidas de superfície. Adição e subtração de frações homogêneas. } \\
\text { Processos de redução à unidade. Conhecer os números simples, compostos, primos, } \\
\text { múltiplos e primos entre si. Reconhecimento dos números primos. Características da } \\
\text { divisibilidade. }\end{array}$ \\
\hline $4^{\circ}$ ano & $\begin{array}{l}\text { Recapitulação do } 3^{\circ} \text { ano. Divisão por cancelamento. Máximo divisor comum. Mínimo } \\
\text { múltiplo comum. Números inteiros, fracionários e mistos. Valor das frações conforme } \\
\text { seus numeradores e seus denominadores. Redução de frações. Extração de inteiros. } \\
\text { Transformar os números inteiros e os mistos em fração. As quatro operações sobre frações } \\
\text { ordinárias. Dízimas periódicas - geratrizes. Unidades principais do sistema métrico. } \\
\text { Adição, subtração, multiplicação e divisão métrica. Redução métrica. Números } \\
\text { complexos. Razão. Princípios de proporção. Regra de três simples. Divisão em partes } \\
\text { proporcionais. Porcentagem. Juros, juros simples. }\end{array}$ \\
\hline
\end{tabular}

Fonte: Decreto S. C., 1914a.

A seleção e a disposição dos saberes aritméticos no programa, conforme indicado no Quadro 1, suscitam algumas questões. Primeiramente, observa-se que os conteúdos se desenvolvem pelo aumento crescente de dificuldade e são aprofundados progressivamente, de maneira que os conhecimentos exigidos nos anos mais avançados dependam essencialmente daqueles aprendidos nos anteriores.

Seguindo este princípio, é notório o fato de que a quantidade de conteúdo prescrita para os dois primeiros anos de curso era significativamente menor do que nos posteriores. No caso do primeiro ano, era indicado basicamente o ensino dos rudimentos da Aritmética, em especial da noção de número e das quatro operações básicas. Destacam-se as seguintes recomendações:

O professor muna-se de collecções de objetos iguaes, bem sensiveis á vista dos alumnos, pelas suas dimensões - lugar em que estejam colocados - e estabeleça palestras encaminhando o ensino, de modo que, apresentada uma collecção - ora de tres, ora de quatro, de seis, sete, etc., dez objetos - eles divulguem e digam quantos são, ex:

- Paulo, quantas taboinhas tenho aqui?

- Quatro taboinhas.

- (Retirando as mãos atraz das costas e apresentando a coleção augmentada).

- E agora?

- Nove taboinhas.

- E agora, Julio?

- Dez taboinhas

(Pratiquem bem estes exercicios variando o emprego das quantidades das collecções de objetos e augmentando-as paulatinamente até 20). (Decreto S.C., 1914a, p. 21) 
http://periodicos.sbu.unicamp.br/ojs/index.php/zetetike

As orientações evidenciadas no trecho anterior mostram que o método adotado nessa etapa dá ênfase ao empírico, à observação, ao ver, ao tocar e ao sentir. As "palestras" proferidas pelos professores objetivavam despertar o sentido da observação no aluno. Esperava-se que ele descobrisse por si mesmo as primeiras ideias do número por meio do contato com os objetos disponibilizados. Apesar disso, as indicações ainda eram voltadas às ações do professor, para aquilo que o docente deveria ou não realizar nas fases educativas. Ou seja, as práticas de ensino permaneciam centradas no protagonismo do professor e não no da criança.

Além disso, observa-se que para o ensino dos números e das quatro operações eram realizados processos de união e separação dos objetos de uma coleção. Esse modo é semelhante à estrutura das atividades apresentadas em Palestras sobre o ensino, de Francis Parker. Para o autor, as primeiras ideias de número e de suas relações devem ser obtidas diretamente pelos sentidos e, quanto às quantidades, pelas repetidas limitações de números de coisas. Considera ainda que as operações aritméticas se reduzem a um dos processos de unir ou separar: reunindo números desiguais (fazendo deles um todo) obtém-se a adição; reunindo números iguais pratica-se a multiplicação; o inverso desses constituem a subtração e a divisão, respectivamente.

A aprendizagem dos números de um a vinte exigiria primeiramente a compreensão das quantidades iguais que formam ou que se contêm em um número, depois as partes iguais de um número, e finalmente, quantidades quaisquer que formam ou que se contêm em um número. Por exemplo, se uma criança está aprendendo o número quatro, o professor deve conduzi-la habilmente de modo que ela descubra "quantas vezes 1 e quantas vezes 2 se contêm em 4; que 3 e 1 fazem 4, e que 1 e 3 também fazem 4”. (Parker, 1909, p. 102). Isto implica diretamente em dois fatos: o ensino dos números e suas operações tornam-se demorados; as quatro operações básicas devem ser ensinadas simultaneamente.

Embora seja disponibilizado um tempo expressivo para o ensino dos números e suas relações nos dois primeiros anos do curso primário, parece que há uma ruptura no processo sugerido por Parker nas prescrições do terceiro e do quarto ano. Nessas séries, eram abolidos os exemplos de exercícios e as notas explicativas para os professores, já os conteúdos apareciam em maior quantidade e apresentavam um caráter mais abstrato e complexo - ainda que, em alguns momentos, se valorizasse o conhecimento prático, como os exercícios de medição de alturas pela sombra no último ano.

A classificação dos alunos aparece como novo dispositivo para a organização pedagógica dos Grupos Escolares baseada na divisão dos estudantes em seções por nível de desempenho. Estas observações surgem especificamente para o primeiro ano durante as prescrições para a matéria de leitura, quando, por meio da atividade de leitura da cartilha, o professor deveria dividir a classe em três seções (A, B e C), conforme aproveitamento dos alunos. Essa divisão da turma, constituída durante a leitura, permanece também em algumas atividades de Aritmética, conforme Quadro 1. 
http://periodicos.sbu.unicamp.br/ojs/index.php/zetetike

As questões ressaltadas até o momento permitem compreender que o trabalho pedagógico esperado pelos reformadores da instrução pública catarinense para a matéria de Aritmética estava relacionado à atividade prática que o aluno deveria realizar sobre os objetos pela observação direta dos fatos: o conhecimento passa pela percepção do aluno diante objeto e não pela memorização desse conhecimento pelo aluno. Assim, o método basilar desse programa investe no ensino "concreto, racional e ativo, denominado ensino pelo aspecto, lições de coisas ou ensino intuitivo" (Valdemarin, 1998, p. 68):

todas as atividades propostas devem motivar o aprimoramento da observação e da inteligência consistindo em imitações das formas e objetos existentes no cotidiano da criança. ... A superioridade do método intuitivo consiste na colocação de fatos e objetos para serem observados pelos alunos, criando situações de aprendizagem em que o conhecimento não é meramente transmitido e memorizado, mas emerge no entendimento da criança a partir dos dados inerentes ao próprio objeto. (70)

O Regimento Interno dos Grupos Escolares de 1914, assim como o programa de ensino, realçava as concepções do método intuitivo como orientadoras para o ensino de Aritmética:

Art. 52. - O ensino de arithmetica terá em vista desenvolver o raciocinio, ministrar noções necessárias á vida pratica. As denominações e as definições, succintas, dos diversos assumptos, e que se façam necessarias, serão deduzidas dos exemplos, pelos alunos [ênfase adicionada]. (Decreto S. C., 1914b, p.18)

Por meio deste excerto, é possível assinalar as finalidades almejadas pelos reformadores catarinenses para o ensino de Aritmética: desenvolver o raciocínio e proporcionar conhecimentos necessários à vida prática. Parker (1909, p. 96) argumenta em seu livro que a Aritmética tem as funções de exercitar o poder de calcular com exatidão e rapidez, e de desenvolver logicamente o poder de raciocinar. Além disso, a exatidão e a celeridade na realização de um bom trabalho nos exercícios das operações fundamentais educam, nas crianças, a faculdade da atenção.

Cabe ressaltar que os materiais didáticos difundidos para uso em sala de aula, em tempos de Pedagogia Moderna no estado, compreendiam os objetos concretos, como pedrinhas e taboinhas, e os Quadros de Parker, em substituição aos livros de textos para memorização.

De acordo com Valente (2014), os Quadros de Parker integram um conjunto de gravuras organizado e técnico, cuja finalidade é facilitar a condução metódica do ensino pelo professor. As gravuras são acompanhadas de orientações e instruções aos docentes, indicando a maneira de utilizá-las para o ensino dos conteúdos aritméticos; exemplos e perguntas são recomendados para a condução das aulas e para o avanço na leitura de cada um dos quadros. Assim, sob a égide das lições de coisas - da pedagogia do olhar, ver, observar -, o professor deveria fazer uso desse objeto por meio da exposição oral. Em síntese: os Quadros de Parker 
http://periodicos.sbu.unicamp.br/ojs/index.php/zetetike

representam a maneira de abordar o ensino de Aritmética de forma intuitiva na moderna pedagogia do ensino primário ${ }^{12}$.

Por sua vez, os livros didáticos simbolizavam o velho e ultrapassado ensino tradicional, baseado na memorização e na repetição. Para a Pedagogia Moderna era necessário modificar completamente os métodos seguidos nas escolas primárias. Desejava-se que o livro e o texto se retirassem ante a "coisa", ante a realidade. "A educação escolar deveria seguir as indicações da natureza", ou seja, "as crianças deveriam ser educadas tal como a natureza educou o gênero humano: intuitivamente, empiricamente, repetindo em suas vidas os estágios de desenvolvimento de toda a humanidade" (Teive, 2014, p. 157). Dessa forma, nos Grupos Escolares as coisas deveriam tomar o lugar dos livros, e para isso determinou-se a proibição de o "uso dos alumnos decorarem compendios ou mesmo apontamentos fornecidos ou dictados pelos professores" (Decreto S. C., 1914b, p.18).

Tanto para a matéria de Aritmética, como para as outras matérias escolares, não foi estabelecido um compêndio didático para utilização pelos alunos em sala. Os únicos livros adotados e aprovados para os Grupos Escolares ao longo de toda a primeira década no século XX foram basicamente os livros de leituras, de caráter moral e cívico e as cartilhas (Decreto S. C. 1911b). No entanto, apesar de tal proibição, o inspetor Orestes Guimarães (1911) realizou em "Parecer sobre a Adopção de Obras Didacticas" uma seleção das obras mais adequadas para compor as bibliotecas dos Grupos Escolares e as bibliotecas dos Inspetores. Os livros de Aritmética indicados foram: Arithmetica Escolar, livro do mestre, Ramon Roca Dordal; Calculo mental, Brasilicus; Calculo Arithmetica, Alfredo Soares; Soluções e respostas de Arithmetica e Systema Metrico, U. Auvert.

\section{A Reforma Elpídio Barbosa: o Programa para os Estabelecimentos de Ensino Primário}

A reforma no ensino público catarinense em 1946 foi coordenada pelo professor Elpídio Barbosa e visava conformar o estado de Santa Catarina com as renovações educacionais que passaram a vigorar no País após a promulgação da Lei Orgânica Federal do Ensino Primário. Tais renovações eram representadas pela expressão Escola Nova ${ }^{13}$.

No início do século XX, o movimento reformador da Escola Nova foi destaque nos debates educacionais em todo o mundo. No Brasil, os discursos baseados nesse movimento

\footnotetext{
${ }^{12}$ A pesquisa de Costa (2010, p. 119) aponta que, possivelmente, os Quadros de Parker foram fundamentados no Método Grube. Em síntese, esse método consiste em levar os alunos por si mesmos, e de modo intuitivo, a realizarem as operações fundamentais do cálculo elementar.

${ }^{13}$ Convém esclarecer que, apesar de operarem sob o mesmo slogan - a "Escola Nova" ou a "Escola Ativa" -, diferentes projetos educacionais estavam em debate, reunidos, no entanto, pelo discurso da renovação educacional. Segundo Valdemarin (2010, p. 208), a Escola Nova acoplava um conjunto de ideias que defendiam a instituição escolar como lugar privilegiado para a construção de um projeto político-social num período marcado pela recomposição de forças dos grupos participantes do poder.
} 
http://periodicos.sbu.unicamp.br/ojs/index.php/zetetike

adquiriram notoriedade em meados de 1920, quando emergiu uma intensa discussão acerca das diretrizes a serem delineadas para a educação no País, objetivando, sobretudo, a constituição da nacionalidade brasileira. Na década de 1930, a Escola Nova alcançou seu auge devido à ação direta dos "intelectuais escolanovistas" e dos agentes do governo, que desenvolveram dispositivos próprios de produção, debates e disseminação das principais questões educacionais defendidas pelo movimento (Monarcha, 2009).

Seguindo este enredo, na década de 1930, o governo catarinense mostrou-se atento às novas questões que surgiam no campo educacional brasileiro. Contudo, os cursos primários e seus programas de ensino não sofreram alterações significativas naquele momento. Somente com a Reforma Elpídio Barbosa os representantes da educação no estado investiram de fato na adequação do currículo da escola primária aos postulados da Escola Nova. Dessa forma, instituiu-se o inovador Programa para os Estabelecimentos de Ensino Primário $^{14}$.

Nesse programa, uma nova proposta quanto à organização das matérias foi inaugurada: os saberes escolares foram agrupados por eixos temáticos que reúnem um conjunto de matérias afins a serem ensinadas. Cada eixo foi dividido em três itens: o primeiro explicitava os objetivos do ensino para cada ano escolar; o segundo apresentava um sumário da matéria com os conteúdos de ensino; e por fim, o último fornecia sugestões práticas em relação aos conteúdos indicados no sumário. Após a exposição destes itens para os quatro anos escolares, eram incluídas, ainda, recomendações ao professor.

Diante de tantas inovações, surgem os seguintes questionamentos: como o ensino de Aritmética deveria se configurar tendo em vista as ideias escolanovistas? As antigas práticas e materiais didáticos teriam desaparecido totalmente por ocasião da incorporação dos princípios da Escola Nova em Santa Catarina?

\section{A Aritmética Na Reforma Elpídio Barbosa: por uma escola ativa}

O Programa para o curso primário de 1946 apresenta os saberes aritméticos incluídos na matéria "Programa de Iniciação Matemática". O sumário para cada série é disposto em três áreas temáticas: Aritmética, Geometria e Problemas e exercícios. Em relação aos conteúdos específicos de Aritmética, os assuntos são distribuídos em subtópicos numa ordem sequencial de desenvolvimento, conforme se observa no Quadro 2:

Quadro 2 - Síntese do Programa para os Estabelecimentos de Ensino Primário S.C. (Aritmética) - 1946

\begin{tabular}{|c|l|}
\hline $1^{\text {a }}$ série & $\begin{array}{l}\text { Numeração: noção de unidade e coleção. Formação de coleção. Representação gráfica } \\
\text { das coleções - símbolos numéricos até 9. Como se desfaz uma coleção: subtração } \\
\text { sucessiva de um elemento ou unidade. O símbolo zero. Comparação de coleções. Noção }\end{array}$ \\
\hline
\end{tabular}

\footnotetext{
${ }^{14}$ A estrutura da educação pública no estado foi modificada consideravelmente na reforma Elpídio Barbosa. O ensino primário foi dividido nas categorias: Fundamental e Supletivo. O Ensino Primário Fundamental constituía-se pelos cursos Elementar (4 anos) e Complementar (1 ou 2 anos). Os grupos escolares, as escolas isoladas e as escolas reunidas representavam o curso elementar (Decreto S. C., 1946a).
}

Zetetiké, Campinas, SP, v.24, n.2, maio/ago.2016, p.208-224

ISSN 2176-1744 
http://periodicos.sbu.unicamp.br/ojs/index.php/zetetike

\begin{tabular}{|c|c|}
\hline & $\begin{array}{l}\text { de ordem numérica até nove. Noção de número par e noção de número ímpar. Coleções de } \\
\text { dez e de doze objetos - dezena e dúzia, respectivamente. Representação gráfica até } 50 . \\
\text { Estudo dos números até } 50 \text { e, em seguida, até } 100 \text { de forma análoga ao que se fez até } 10 . \\
\text { Números romanos até XII. Operações fundamentais: Adição e subtração de números } \\
\text { simples. Sinais dessas operações e o de igualdade. Cálculos dispostos em colunas. Noção } \\
\text { de dobro e de metade de um número ou coleção. Meia dezena e meia dúzia. Moedas: O } \\
\text { cruzeiro e suas divisões. Representação gráfica. Troco. }\end{array}$ \\
\hline $2^{a}$ série & $\begin{array}{l}\text { Numeração: Recapitulação do programa do } 1^{\circ} \text { ano. Centenas. O zero, seu valor e sua } \\
\text { utilidade. Coleção de centenas - noção de milhar. Leitura e escrita, composição e } \\
\text { decomposição de números de } 3 \text { e } 4 \text { algarismos. Série natural dos números inteiros até } \\
\text { 10.000. Ordem crescente e decrescente. Números pares e ímpares. Numeração romana até } \\
\text { XXX. Operações fundamentais: Adição e subtração de números compostos de } 2 \text { e } 3 \\
\text { algarismos. Provas reais. Noção de multiplicação pela repetição de parcelas iguais. Dobro, } \\
\text { triplo, quádruplo e quíntuplo. Sinal e nomenclatura da multiplicação. Multiplicação com o } \\
\text { multiplicador simples. O zero na multiplicação. Divisão por números simples. Sinal e } \\
\text { nomenclatura da divisão. Simplificação da divisão por múltiplos de } 10 \text {. Divisibilidade por } \\
2,5 \text { e } 10 \text {. Prova real. Fraçães: Fração ordinária considerando os termos da fração como } \\
\text { dividendo e divisor. Décimos e centésimos em forma decimal. Soma e subtração de } \\
\text { centésimos. Unidade de medida: Conhecimento prático do metro, litro, quilo. } \\
\text { Conhecimento da hora. Moedas: O cruzeiro e sua subdivisão. Comparação com } 1000 \text {, } \\
500,200 \text { e } 100 \text { réis. }\end{array}$ \\
\hline $3^{a}$ série & $\begin{array}{l}\text { Numeração: Recapitulação do programa do ano anterior. Formação dos números } \\
\text { compreendidos entre duas dezenas de milhar consecutivas. Leitura, escrita, composição e } \\
\text { decomposição de números até centena de milhar. Numeração romana até C. Operações } \\
\text { fundamentais: Adição e subtração (números inferiores a 100.000). Multiplicação e } \\
\text { divisão de números composto. Provas reais. Multiplicação e divisão por potências de } 10 \text {. } \\
\text { Divisibilidade por } 2,3,5 \text { e } 9 \text {. Frações: Frações ordinárias e decimais. Equivalência de } \\
\text { frações ordinárias. Frações como parte do inteiro. O número decimal. As quatro operações } \\
\text { sobre frações e números decimais. Movimento da vírgula. Unidades de medida: Metro, } \\
\text { litro, quilograma, segundo. Seus símbolos, múltiplos e submúltiplos usuais. Aplicação do } \\
\text { estudo das frações decimais às medidas de comprimento, capacidade e massa. Moedas: } \\
\text { moedas e cédulas. }\end{array}$ \\
\hline $4^{a}$ série & $\begin{array}{l}\text { Numeração: Revisão do estudo feito na série anterior. Formação dos números até bilhões } \\
\text { - leitura e escrita. Conhecimento dos símbolos romanos D e M através das datas } \\
\text { históricas. Valor absoluto e relativo de um número. Operações fundamentais e } \\
\text { potenciação: Estudo completo das quatro operações. Prova dos nove. Noção de potência. } \\
\text { Propriedades dos números: Números primos e múltiplos. Decomposição do número em } \\
\text { fatores primos. Números primos entre si. Mínimo múltiplo comum e máximo divisor } \\
\text { comum. Frações: Fração ordinária própria, imprópria, redutível, irredutível, homogêneas } \\
\text { e heterogêneas. Números mistos. Simplificação de frações. Comparação de frações. As } \\
\text { quatro operações sobre frações ordinárias. Unidade de medida: Noção de escala. } \\
\text { Unidades de área e ângulo. Minutos e segundos como medida de tempo e ângulo. Medidas } \\
\text { de temperatura. Sistema monetário brasileiro: moedas e cédulas. }\end{array}$ \\
\hline
\end{tabular}

Fonte: Decreto S. C., 1946b.

A organização dos saberes aritméticos, conforme indicado no Quadro 2, possibilita a aprendizagem gradual e progressiva dos conteúdos, incorporando gradativamente novos conceitos àqueles já trabalhados. A indicação da revisão do estudo realizado na série anterior, 
http://periodicos.sbu.unicamp.br/ojs/index.php/zetetike

antes da introdução de novos conhecimentos, é um indício da permanência de certas práticas estabelecidas no programa de 1914.

O sumário destacado no Quadro 2 foi prescrito visando à normatização dos conteúdos a serem estudados em cada série escolar. Apesar de o Programa apresentar algumas indicações de ordem metodológica, a forma como o professor deveria ensinar os conteúdos era esclarecida minuciosamente no item "sugestões práticas" e "observações finais". Em linhas gerais, orientava-se que o ensino fosse dado intuitivamente e por processos ativos (Decreto S. C., 1946b, p. 12). O ensino por meio da intuição ficava a cargo da utilização de materiais concretos, como madeiras e grãos diversos, já os processos ativos eram atingidos por meio de jogos, modelagem, problemas práticos, entre outros.

A manutenção do método intuitivo, principalmente para os dois primeiros anos, sugere mais uma vez uma sólida herança pedagógica da Reforma Orestes Guimarães no programa de 1946. No entanto, é possível identificar também a influência das concepções escolanovistas no currículo do curso primário mediante indicação de processos ativos, além da estreita relação entre ensino e prática.

Lourenço Filho (1978), um dos principais intelectuais escolanovistas do país, defendia o papel ativo do aluno no processo educativo, pois os alunos aprenderiam "observando, pesquisando, perguntando, trabalhando, construindo, pensando e resolvendo situações problemáticas apresentadas" em relação a um ambiente de coisas e ações práticas ou em situações de sentido social e moral, reais ou simbólicos (p. 151), por isso a importância dada às atividades variadas.

Além desses aspectos, a Escola Nova propunha um novo olhar sobre a criança e sua inserção na sociedade, pois compreendia que a escola não poderia estar alheia aos problemas sociais, como salienta Lourenço Filho (p. 249), "a dimensão própria da ação educativa é de ordem social e cultural” (p. 249). Dessa forma, a escola deveria formar a criança para viver em sociedade, conformando as necessidades de cada indivíduo ao meio social. Esta ideia pode ser verificada no Programa da $4^{\mathrm{a}}$ série:

por meio de palestras a respeito de visitas a escolas industriais, às oficinas da Estrada de ferro, a um estaleiro, ..., a outros centros de trabalho onde os alunos possam coletar dados para organização de problemas e planejamento de atividades em classe, procurar-se-á entrever as preferências dos escolares para uma profissão adequada às suas tendências naturais, afim de orientá-los na escolha de uma atividade, após o curso primário. (Decreto S. C., 1946b, p. 17)

Corroborando essas considerações, o estudo de Arruda, Flores e Brigo ${ }^{15}$ (2010, p. 128) evidencia a preocupação do programa de Aritmética com a formação intelectual da

\footnotetext{
15 As autoras apresentam uma análise sobre como o ensino de matemática foi organizado e articulado oficialmente nas escolas catarinenses. Para isso, tomam como eixo de referência e lugar de análise a Lei Orgânica do Ensino Primário e os Programas de Ensino Primário de Santa Catarina, ambos de 1946. O foco do estudo recai sobre os saberes aritméticos e geométricos nas escolas de ensino primário fundamental elementar e complementar, além dos cursos supletivos.
} 
http://periodicos.sbu.unicamp.br/ojs/index.php/zetetike

criança, voltada ao desenvolvimento do cálculo, sobretudo das quatro operações e das noções de medidas básicas. As indicações para o emprego de problemas relacionados com as experiências da vida infantil, de utilidade prática e com a vida econômica e profissional do país demonstram uma proposta carregada por uma ideia funcional ou de que "serve para alguma coisa" - neste caso, para formar o indivíduo desde criança para o trabalho.

Cabe ressaltar que os objetos manipuláveis foram os únicos materiais didáticos indicados para o ensino da Aritmética escolar, pois não foram encontradas recomendações explícitas para a utilização dos Quadros de Parker, nem de qualquer outro impresso didático. Em seu lugar foram sugeridos os objetos concretos (como tornos de madeira, palitos e grãos diversos), os jogos educativos (por exemplo, jogo de bolas, corrida de automóveis, dominó, cinema e feira), os trabalhos manuais com desenhos e modelagem, os quadros estatísticos publicados em noticiários, os problemas sobre dados da vida real, e outros. Inaugurava-se, assim, uma retórica afinada com as renovações educacionais advindas do Movimento da Escola Nova brasileiro, representado, sobretudo, por Lourenço Filho.

Contudo, De Paula e Teive (2014) ${ }^{16}$ identificaram em seus estudos que o manual Didática da Escola Nova, de Alfredo M. Aguayo, foi uma das obras de maior circulação no estado entre os anos de 1946, 1948 e 1949. Esse manual não se configura propriamente como um livro didático de Matemática, mas, por tratar das várias matérias do ensino primário, contempla orientações para o ensino de Aritmética.

É interessante observar que Aguayo faz severas críticas ao método Grube em seu livro, como fica evidenciado no trecho destacado:

Os partidários do método de Grube pretendem que a aprendizagem das operações fundamentais se faça simultaneamente com relação a cada grupo ou número da série de unidades; esse processo, porém, não é recomendável. É preferível dividir as dificuldades do cálculo, e ensinar primeiro uma só operação durante certo tempo, depois outra e assim sucessivamente [ênfase adicionada]. (Aguayo citado por Valente, 2014, p. 73)

Ou seja, o autor não concordava com a ideia de ensinar as diferentes operações aritméticas simultaneamente, como defendia Francis Parker em suas Palestras sobre o ensino. Perante a concepção de Aguayo, esse método de aprendizagem dos números e suas relações caracteriza-se como um modo ultrapassado de ensino de Aritmética na escola primária.

Contraditoriamente, nas observações finais do programa de iniciação matemática para o primeiro ano, é indicado que "fornecendo aos alunos objétos fáceis de manusear..., o professor ensinar-lhes-á simultaneamente todas as operações que se pódem efetuar com um dado número, fazendo-os descobrir todas as combinações possíveis entre êle e os números menores" (Decreto S. C., 1946b, p. 17). Nesse sentido, existia certa contradição entre o que

\footnotetext{
${ }^{16}$ As autoras realizaram um levantamento nos Comunicados escritos por professores e professoras dos grupos escolares de Santa Catarina a partir de Reuniões Pedagógicas - consideradas na pesquisa como estratégias do Departamento de Educação do Estado de Santa Catarina - que aconteciam regularmente nos grupos escolares com o intuito de adequar as práticas dos docentes ao postulado escolanovista (De Paula \& Teive, 2014).
}

Zetetiké, Campinas, SP, v.24, n.2, maio/ago.2016, p.208-224

ISSN 2176-1744 
http://periodicos.sbu.unicamp.br/ojs/index.php/zetetike

era prescrito na esfera normativa para os docentes e o manual didático utilizado como orientador das aulas.

Cabe salientar, por fim, que Aguayo defendia em seu livro o princípio da atividade discente como eixo central da prática docente. $\mathrm{O}$ autor recomenda que o professor incentive seus alunos a terem sua própria iniciativa e a usarem da criatividade a serviço da aprendizagem da Aritmética. Logo, o professor deveria restringir sua atuação apenas para estimular, dirigir e auxiliar os alunos, quando fosse necessário. Essas orientações são fundamentadas nos ideais escolanovistas e vão de encontro com a proposta dos Quadros de Parker e com a prática das lições de coisas.

\section{Considerações finais}

A análise dos Programas de Ensino 1914 e 1946, fontes de estudo deste artigo, permitiu delinear dois cenários: o primeiro, no qual a matriz pedagógica do tipo "moderna", alicerçada pelo método intuitivo e pela prática das lições de coisas, caracterizou uma renovadora formatação para o ensino da Aritmética nos grupos escolares; e o segundo, no qual as ideias advindas da Escola Nova, especialmente no que se refere ao princípio da escola ativa, introduziram, de forma associada às antigas práticas intuitivas, novos modos de conceber o ensino dos conhecimentos aritméticos nos cursos primários.

Nas primeiras décadas do período republicano, o método intuitivo representou a modernidade pedagógica mais evidente dos grupos escolares catarinenses, identificado não apenas pela importância dos sentidos na aprendizagem inicial dos números, das operações, do cálculo e do raciocínio, mas também pela possibilidade de um ensino ativo, levando a mente da criança a ficar comprometida com a experiência sensorial. A Aritmética escolar em meio à vaga intuitiva tornou-se, pelo menos em âmbito normativo, mais prática e concreta. E a circulação dos materiais didáticos mais modernos, como os Quadros de Parker, sugere que essa mudança seguiu o caminho de uma progressiva intervenção nas práticas tradicionais de ensinar a Aritmética primária em Santa Catarina, promovendo a transformação de um ensino teórico e abstrato para um de caráter mais prático e concreto.

A partir da década de 1940, efetivou-se maior aproximação da escola primária catarinense com os princípios escolanovistas, especialmente devido à promulgação da Lei Orgânica do Ensino Primário do Estado de Santa Catarina, que reorganizou a estrutura educacional catarinense na Reforma Elpídio Barbosa.

O novo programa instituído em 1946 apresentou uma série de inovações de caráter estrutural e didático-pedagógico. Destaca-se que houve considerável redução no rol de conteúdos, quando comparado ao Programa de Ensino de 1914, buscando romper com o viés enciclopédico defendido pela Pedagogia Moderna para implantar um currículo que possibilitasse o contato das crianças com os conhecimentos úteis à vida prática e social por meio da inserção de experiências sociais no próprio meio escolar. A matéria de Aritmética foi extinta do Programa de 1946 e os saberes matemáticos foram agrupados num único eixo 
http://periodicos.sbu.unicamp.br/ojs/index.php/zetetike

temático denominado "iniciação à matemática", que reunia os saberes aritméticos e geométricos.

Por fim, vale ressaltar que se objetivou neste estudo abordar aspectos relacionados ao ensino de Aritmética num período marcado por movimentos educacionais que buscavam estabelecer o que era velho e o que era novo em termos de concepções pedagógicas. No caso aqui analisado, a representação do velho e tradicional foi atribuída ao método intuitivo, e a representação do novo estabeleceu-se sobre as propostas renovadoras da Escola Nova que se desejava consolidar. Compreende-se que o método intuitivo não foi abolido das práticas escolares de um dia para o outro, assim como a pedagogia ativa não foi introduzida definitivamente nas escolas primárias numa data marcada. Ao contrário, as duas concepções pedagógicas coexistiram e foram apropriadas de diversas formas pelos legisladores catarinenses, pelos inspetores escolares, pelos diretores e pelos próprios professores.

\section{Referências}

Aguayo, A. M. (1935). Didática da escola nova. São Paulo: Cia. Editora Nacional. Retirado em 06 de março de 2016, de <https://repositorio.ufsc.br/handle/123456789/116427>.

Arruda, J. P. de, Flores, C. R., \& Brigo, J. (2010). A matemática nos programas oficiais para o ensino primário de Santa Catarina. In C. R. Flores, \& J. P. de Arruda. A Matemática Moderna nas escolas do Brasil e Portugal: Contribuições para a história da educação matemática (pp. 117-142). São Paulo: Annablume.

Chervel, A. (1990). História das disciplinas escolares: reflexões sobre um campo de pesquisa. Teoria \& Educação, 2(1), 177-229.

Costa, D. A., (2010). A Aritmética Escolar no ensino primário brasileiro: 1890-1946. Tese de Doutorado em Educação Matemática, Pontifícia Universidade Católica de São Paulo, São Paulo, SP.

Costa, D. A., \& Souza, T. S. (2014). Os Programas de Ensino dos Grupos Escolares Catarinenses: um estudo sobre a aritmética escolar, 1910-1946. In D. A. da Costa, \& W. R. Valente. Saberes matemáticos no curso primário: o que, como e por que ensinar? (pp. 169-189). São Paulo: Editora Livraria da Física.

De Paula, M. F. B. F. W., \& Teive, G. M. G. (2014). Disciplina em tempos escolanovistas: relações de autoridade e liberdade no cotidiano dos grupos escolares catarinenses (1946-1949). In Anais do $10^{\circ}$ Congresso Luso Brasileiro de História da Educação. Curitiba: PUCPR.

Fiori, N. A. (1991). Aspectos da evolução do ensino público: ensino público e política de assimilação cultural no Estado de Santa Catarina nos períodos Imperial $e$ Republicano. Florianópolis: Editora da UFSC.

Guimarães, O. de O. (1911). Parecer sobre a adoção de obras didáticas. Florianópolis: Gap. Typ. D'O dia. Retirado em 06 de março de 2016, de <https://repositorio.ufsc.br/handle/123456789/101130>. 
http://periodicos.sbu.unicamp.br/ojs/index.php/zetetike

Julia, D. (2001). A cultura escolar como objeto histórico. Revista Brasileira de História da Educação, 1(1), 9-43.

Lourenço Filho, M. B. (1978). Introdução ao estudo da Escola Nova (13a ed.). São Paulo: Melhoramentos.

Monarcha, C. (2009). Brasil arcaico, escola nova: ciência, técnica e utopia nos anos 19201930. São Paulo: Ed. UNESP.

Nóbrega, P. de. (2003). Grupos escolares: modernização do ensino e poder oligárquico. In N. Dallabrida. Mosaico de escolas: modos de educação em Santa Catarina na primeira república (pp. 253-280). Florianópolis: Cidade Futura.

Parker, F. (1909). Palestras sobre Ensino. Campinas: Typ. "Livro Azul" - A.B. Castro Mendes. Retirado em 06 de março de 2016, de <https://repositorio.ufsc.br/handle/123456789/96571>.

Teive, G. M. G. (2007). O professor paulista Orestes Guimarães e a modernização da instrução pública catarinense (1911-1918). Cadernos de História da Educação, 6(1), 107-120.

Teive, G. M. G. (2014). Pedagogia moderna no Brasil: primeiras discussões e experiências práticas (final do século XIX - início do XX). Revista Mexicana de Historia de la Educación, 2(4), 153-172.

Teive, G. M. G., \& Dallabrida, N. (2011). A escola da República: Os grupos escolares e a modernização do ensino primário em Santa Catarina (1911-1918). Campinas: Mercado de Letras.

Valdemarin, V. T. (1998). Método Intuitivo: os sentidos como janelas e portas que se abrem para um mundo interpretado. In R. F. de Souza, V. T. Valdemarina, \& J. S. de Almeida (Orgs.), O legado educacional do século XIX (pp. 63-105). Araraquara: UNESP, Faculdade de Ciências e Letras.

Valdemarin, V. T. (2010). História dos métodos e materiais de ensino: a escola nova e seus modos de uso. São Paulo: Cortez.

Valente, W. R. (2014). Lourenço Filho e o moderno ensino de aritmética: produção e circulação de um modelo pedagógico. História da Educação, 18(44), 61-77.

Vidal, D. G. (2005). Culturas escolares: estudo sobre prática de leitura e escrita na escola pública primária (Brasil e França, final do século XIX). Campinas: Autores Associados.

\section{Legislação}

Decreto S.C. $n$. 587, de 22 de abril de 1911. (1911a). Programa dos grupos escolares e das escolas isoladas do estado de Santa Catarina. Joinville: Typ. Boehm, Acervo: APESC. Retirado em 06 de março de 2016, de <https://repositorio.ufsc.br/handle/123456789/99196>.

Decreto S.C._n. 596, de 07 de julho de 1911. (1911b). Florianópolis: Gap. Typ. D’O dia. Acervo da APESC. Retirado em 06 de março de 2016, de <https://repositorio.ufsc.br/handle/123456789/123490>. 
http://periodicos.sbu.unicamp.br/ojs/index.php/zetetike

Decreto S.C. n. 796, de 2 maio de 1914. (1914a). Programa dos grupos escolares e das escolas isoladas do estado de Santa Catarina. Joinville: Typ. Boehm. Acervo: APESC. Retirado em 06 de março de 2016, de <https://repositorio.ufsc.br/handle/123456789/105101>.

Decreto S.C. n. 795, de 2 maio de 1914. (1914b). Regimento Interno dos Grupos Escolares de 1914. Joinville: Typ. Boehm .Acervo: APESC. Retirado em 06 de março de 2016, de https://repositorio.ufsc.br/handle/123456789/105191>.

Decreto-lei S.C. n. 298, de 18 de novembro de 1946. (1946a). Expede a Lei Orgânica do ensino primário. Diário Oficial n. 3.349, 18 nov. 1946, p. 1-4. Florianópolis: Diário Oficial do Estado de Santa Catarina. Acervo: APESC. Retirado em 06 de março de 2016, de <https://repositorio.ufsc.br/xmlui/handle/123456789/122146>.

Decreto S.C. $n$. 3.732, de 12 dezembro de 1946. (1946b). Programa para os estabelecimentos de ensino primário do estado de Santa Catarina. Florianópolis: Gap. Typ. D’O dia. Acervo: APESC. Retirado em 06 de março de 2016, de <https://repositorio.ufsc.br/handle/123456789/99620>.

Submetido em: 06/03/2016

Aceito em: 01/07/2016 